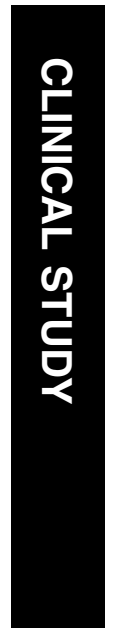

${ }^{1}$ Department of Ophthalmology, Centre for Eye Research, Australia Royal Victorian Eye and Ear Hospital, Melbourne

Australia

${ }^{2}$ Department of Ophthalmology, College of Medicine, University of lowa lowa City, IA, USA

${ }^{3}$ Department of Infectious Diseases, Alfred Hospital Melbourne, Australia

${ }^{4}$ Department of Ophthalmology, St Vincent's Hospital, Sydney, Australia

${ }^{5}$ MitoKor, San Diego CA, USA

${ }^{6}$ Department of Radiation Therapy, University of Texas Medical Branch

Galveston, TX, USA

${ }^{7}$ Department of Medicine Monash University Alfred Hospital

Melbourne, Australia

Correspondence: Dr DA Mackey Centre for Eye Research Australia Royal Victorian Eye and Ear Hospital, 32 Gisborne St East Melbourne, Victoria 3002, Australia E-mail: D.Mackey@ utas.edu.au

Received: 16 April 2002 Accepted in revised form: 25 July 2002

Statement of sponsorship: Neil Howell is Vice President for Research at MitoKor

\title{
Leber's hereditary optic neuropathy triggered by antiretroviral therapy for human immunodeficiency virus
}

\begin{abstract}
Purpose To describe the clinical features of two cases of Leber's hereditary optic neuropathy (LHON) precipitated by antiretroviral treatment for human immunodeficiency virus (HIV) infection. Methods Two cases of LHON (from an expected four new cases a year throughout Australia) were identified in men on treatment for HIV infection.

Results Two HIV-infected men were receiving combination antiretroviral therapy that included nucleoside analogues. Both patients carried the $\mathbf{1 4} 484$ mitochondrial DNA mutation and were distantly related (seventh cousins). Although both men presented with sequential visual loss typical of LHON and one had a known close relative affected by LHON, the correct diagnosis was delayed in both cases. The final visual outcome was profoundly reduced in both instances and cessation of antiretroviral therapy did not result in recovery of vision in one patient. Conclusion Patients with a family history of LHON who require antiretroviral treatment should be warned of the high risk of severe visual loss. The underlying mechanism of antiretroviral side effects may help characterize the other trigger factors for LHON.
\end{abstract}

Eye (2003) 17, 312-317. doi:10.1038/

sj.eye. 6700362

Keywords: Leber's hereditary optic neuropathy; human immunodeficiency virus; antiretroviral

\section{Introduction}

Leber's hereditary optic neuropathy (LHON) is a cause of acute loss of central vision for which mitochondrial DNA (mtDNA) mutations are the
DA Mackey ${ }^{1}$, JH Fingert ${ }^{2}$, JZ Luzhansky ${ }^{3}$, PJ McCluskey ${ }^{4}$, N Howell ${ }^{5,6}$, AJH Hall ${ }^{1}$, AB Pierce ${ }^{3}$ and JF Hoy ${ }^{3,7}$

primary predisposing risk factor. ${ }^{1}$ However, the majority of patients with the disease-causing mtDNA mutations never lose vision. Other genetic or environmental factors are responsible for triggering visual loss, which usually occurs in the third decade of life and which tends to affect men more frequently than women. ${ }^{2}$ On the basis of clinical case reports, numerous environmental factors have been proposed to trigger LHON. These include tobacco smoke, which may be contaminated with cyanide, a well-known mitochondrial toxin. ${ }^{4}$ However, recent work has disputed a relationship between tobacco and alcohol consumption and LHON. ${ }^{5}$ Lüke et al, ${ }^{6}$ Shaikh et $a l_{,}^{7}$ and Warner and $\operatorname{Ries}^{8}$ have all recently reported individual cases of LHON associated with antiretroviral therapy for human immunodeficiency virus (HIV) infection. Antiretroviral drugs of the nucleoside analogue class are known to be associated with mitochondrial toxicity, for example, zidovudine can cause a toxic mitochondrial myopathy. ${ }^{9-11}$ We report two similar cases to describe the severity of the clinical spectrum, and to put this association within the perspective of the relative rarity of the two conditions.

\section{Case report 1}

A 47-year-old (b 1953) Caucasian male presented in June 2000 with acute visual loss and a central scotoma in the left eye. He had had no eye disease previously apart from mild left amblyopia, which was treated with glasses from 3 years of age. There was a known family history of LHON. He was a member of the LHON Tas2 pedigree ${ }^{12,13}$ with the 14484 mutation. His nearest other affected relatives were his mother and uncle. 
The patient was diagnosed with HIV infection in 1986 at age 33 years. In 1990, he was given zidovudine (AZT) for a short period. In 1994, combination antiretroviral therapy with zidovudine and zalcitabine (ddC) was begun. This treatment was discontinued in 1996 because of adverse effects and deteriorating immune function complicated by Pneumocystis carinii pneumonia. The CD4 cell nadir was 200/ $\mu$ l. In May 1997, the patient was started on highly active antiretroviral therapy (HAART) using 3TC, stavudine, and indinavir. This was continued until July 1999 when therapy was changed, because of the development of peripheral neuropathy (secondary to stavudine), to amivudine + zidovudine (Combivir ${ }^{\mathbb{R}}$ ), abacavir, nevirapine, adefovir, and hydroxyurea. Folic acid and vitamin $B_{12}$ levels were normal at this time. In May 2000, the adefovir and hydroxyurea were discontinued. At this time, his CD4 cell count was 500/ $\mu$ l and the HIV viral load was below detectable limits. The patient was a nonsmoker and his daily alcohol intake was 10-20 g/day. His only other medications were creatine and Tribulus natural therapies. He had had a course of Sustanon ${ }^{\circledR}$ (testosterone propionate $20 \mathrm{mg}$, testosterone phenylpropionate $40 \mathrm{mg}$, and testosterone isocaproate $40 \mathrm{mg}$ ) injections for 3 months.

He first noted loss of vision in his right eye in October 2000. On examination 3 months after the onset of visual loss, his acuities were right $6 / 60$ and left $6 / 60$. Visual field testing showed an extensive left central scotoma and a localized right centrocaecal scotoma (Figure 1). His fundus examination showed small slightly pale optic discs with no peripapillary telangiectasia. His retina was otherwise normal and he had no history of cytomegalovirus (CMV) retinitis. Over the subsequent 3 months, his vision deteriorated further and he became depressed. His visual acuity dropped to hand movements for right and left, his visual fields had worsened significantly, and his optic discs showed slightly greater pallor (Figure 2). Given the possibility that his antiretroviral medications were contributing to his visual loss, he elected to stop antiretroviral therapy. His vision, which was now severely affected, did not appear to decline further over the following 2 months. Unfortunately, his AIDS worsened off treatment with his CD4 count dropping to $95 / \mu 1$ and his viral load became detectable at $>500000$. After 7 weeks of ceasing treatment, he was recommenced on antiretroviral treatment with nevirapine $200 \mathrm{mg}$ b.d., ritonovir $100 \mathrm{mg}$ b.d., and saquinavir soft gel $5 \mathrm{mg}$ b.d., a combination that was thought to have the least mitochondrial toxicity. His vision has remained very poor since, with no recovery or further deterioration. However, since recommencing this treatment he has noticed a worsening of the peripheral neuropathy in his feet.

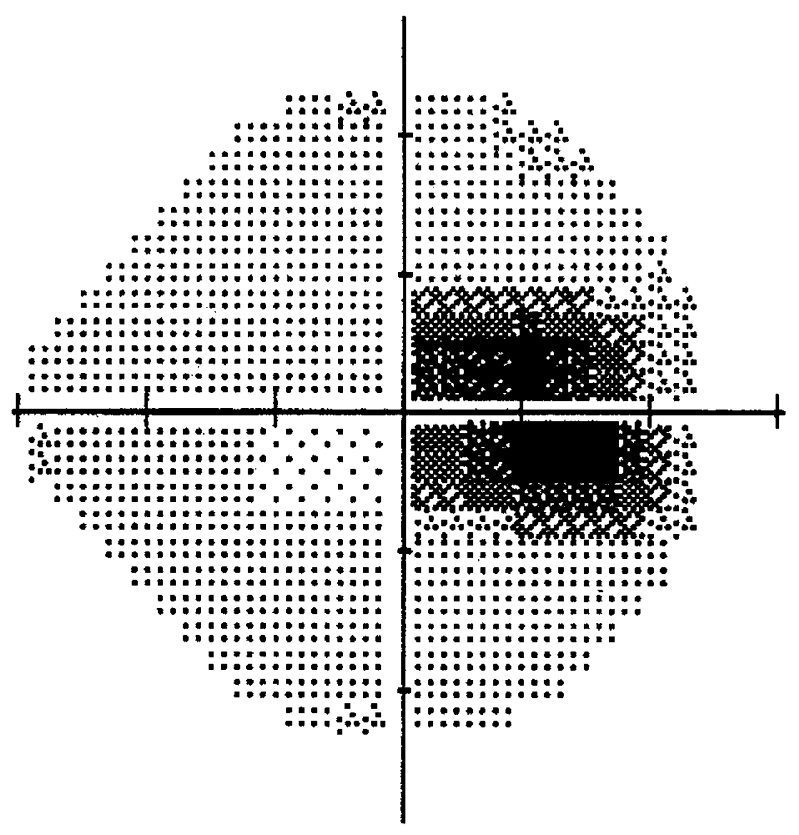

Figure 1 Case 1 right Humphrey 24-2 visual field grey scale plots, 3 months after onset of visual loss, showing centrocaecal scotoma.

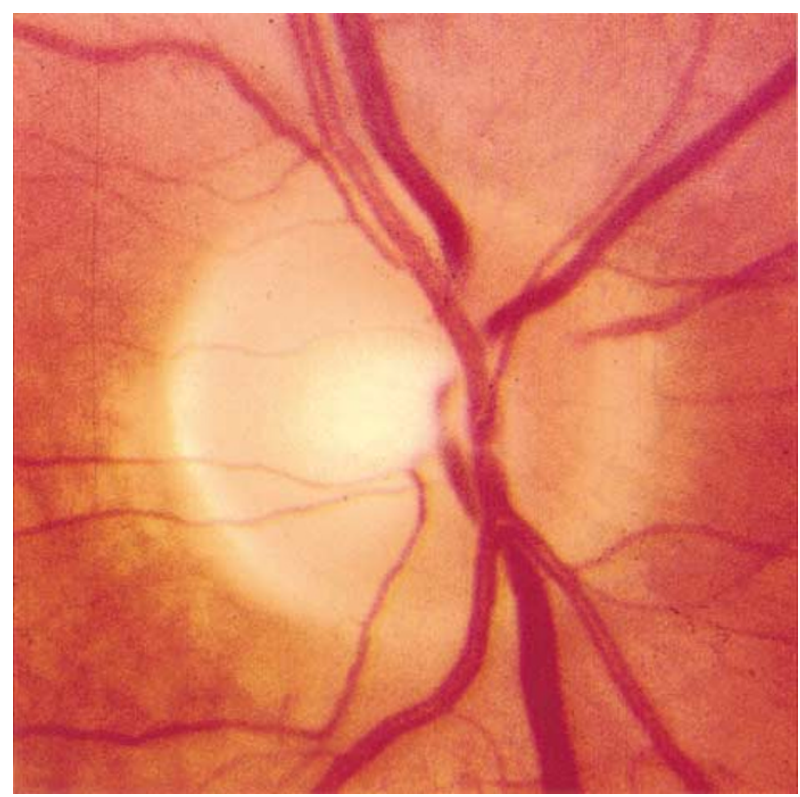

Figure 2 Case 1 right optic disc photograph, 6 months after onset of visual loss, showing moderate optic atrophy.

\section{Case report 2}

A 57-year-old (b 1943) Caucasian male with no known visual problems was diagnosed with HIV infection in 1986. In 1991, when his CD4 cell count was $150 / \mu \mathrm{l}$, he 
commenced antiretroviral therapy with zidovudine monotherapy, and was changed to HAART in 1996. He was treated with stavudine-containing regimens from 1994 until $2000 .{ }^{14}$ His HIV course was complicated by cerebral toxoplasmosis, peripheral neuropathy secondary to ddC and Zalcitabine (ddC), hyperlipidaemia, anaemia secondary to zidovudine, squamous cell carcinoma of the lip, and impaired glucose tolerance. In January 1998, he presented with bilateral floaters and was diagnosed with mild left equatorial (zone 2) CMV retinitis. His vision was $6 / 6$ bilaterally at the time. He received ganciclovir induction and maintenance therapy, and in August 1998 he joined the valganciclovir open-label maintenance safety study. His retinitis remained quiescent for 13 months. In March 1999, he developed CMV retinitis in his right eye periphery (zone 3 ) and was treated with oral valganciclovir reinduction. His vision was right $6 / 4$ and left 6/9 at that time. In August 1999, he experienced a transient episode of ataxia, dizziness, and left hand paraesthesias, which appeared to resolve with cessation of the antiretroviral drug efavirenz. In January 2000, his neurological symptoms returned and progressed, and over the next few months he developed marked lowerlimb wasting, impaired vibration, proprioception, pinprick, light touch sensation in the lower limbs, brisk reflexes, urinary urge incontinence, and loss of peri-anal sensation.

In February 2000, he developed a sudden painless loss of central vision in his right eye. His CMV retinitis was still quiescent in both eyes, but he had slight optic nerve swelling in his right eye that had not been present 10 days earlier, at his last ophthalmology review appointment (Figure 3). His visual acuity was right 6/60 and left $6 / 18$. His colour vision was significantly reduced in his right eye, and visual field testing revealed a diffuse loss of sensitivity and a small centrocaecal defect in his right eye, both consistent with optic neuritis. There was no relative afferent pupillary defect. He had numerous investigations: fluorescein angiogram - normal; lumbar puncture - normal; cerebrospinal fluid (CSF) - negative for CMV polymerase chain reaction (PCR), toxoplasma PCR, herpes simplex virus I and II PCR, varicella zoster virus PCR, and syphilis; HIV viral load in CSF - undetectable; serum cryptococcal antigen - negative; and computerized tomography and magnetic resonance imaging (MRI) of the brain showed no evidence of an optic lesion. Visual evoked potentials demonstrated a prolonged P100 on the right, approximately 6 standard deviations from the normal mean, indicating a lesion of the optic pathways anterior to the chiasm on the right. He received intravenous foscarnet because a viral cause could not be excluded, but when no improvement was detected after 2 weeks

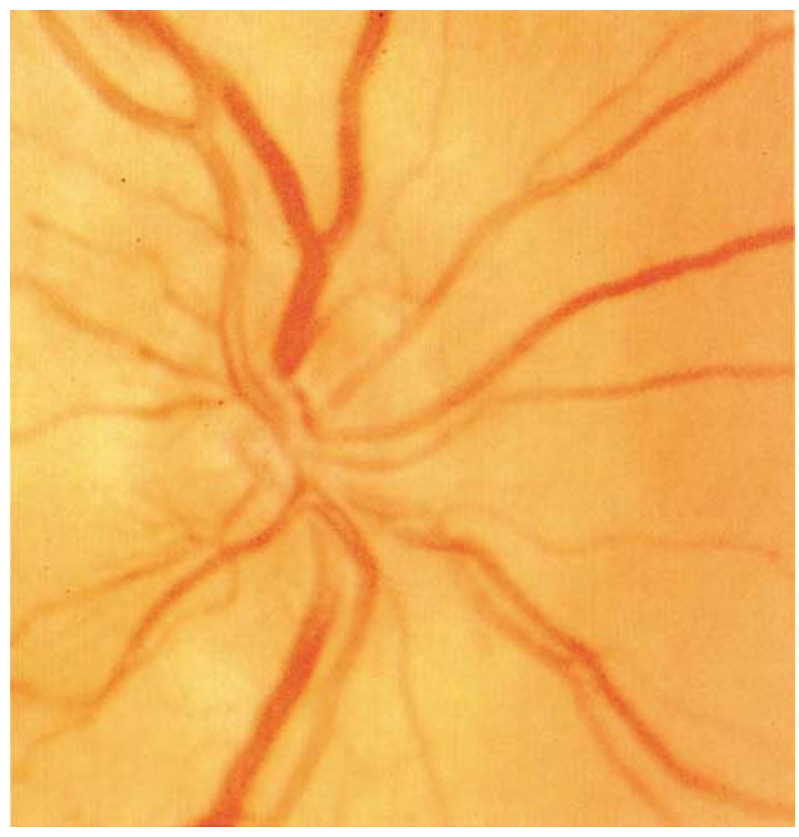

Figure 3 Case 2 right optic disc photograph, 10 days after onset of visual loss in this eye, showing mild optic disc swelling.

this treatment was ceased. He also received a month's course of high-dose prednisolone for presumed immunemediated optic neuritis.

Despite all treatment, his vision worsened. In April 2000, 2 months after his right eye symptoms commenced, his left eye developed identical symptoms and new, left optic nerve swelling. His vision at that time was: right, hand movements; left, count fingers. He received another course of prednisolone for the new optic neuritis. At this time, he became neutropenic and valganciclovir was ceased. His CMV retinitis reactivated and required treatment with cidofovir.

The following month, his sister's son developed a unilateral optic neuropathy. Specimens from case 2 were immediately sent to be tested for LHON. By September 2000, he had no perception of light with either eye and he showed bilateral optic atrophy. MRI now revealed a new increase in signal from both optic tracts. His neurological symptoms worsened to include rigidity (mainly upper body) and tremor (entire body). His lactate level was elevated at $4.5 \mathrm{mmol} / \mathrm{L}$. Another lumbar puncture was performed, but no infective agent was identified. By this stage, he was bed-bound and fully dependent upon nursing care. All antiretroviral medications were ceased and palliative care was instituted. He died 2 months later. This case was briefly reported recently. ${ }^{14}$ This patient was found to be a member of the same 14484 LHON family, with the first case being his seventh cousin (abbreviated pedigree shown in Figure 4). 


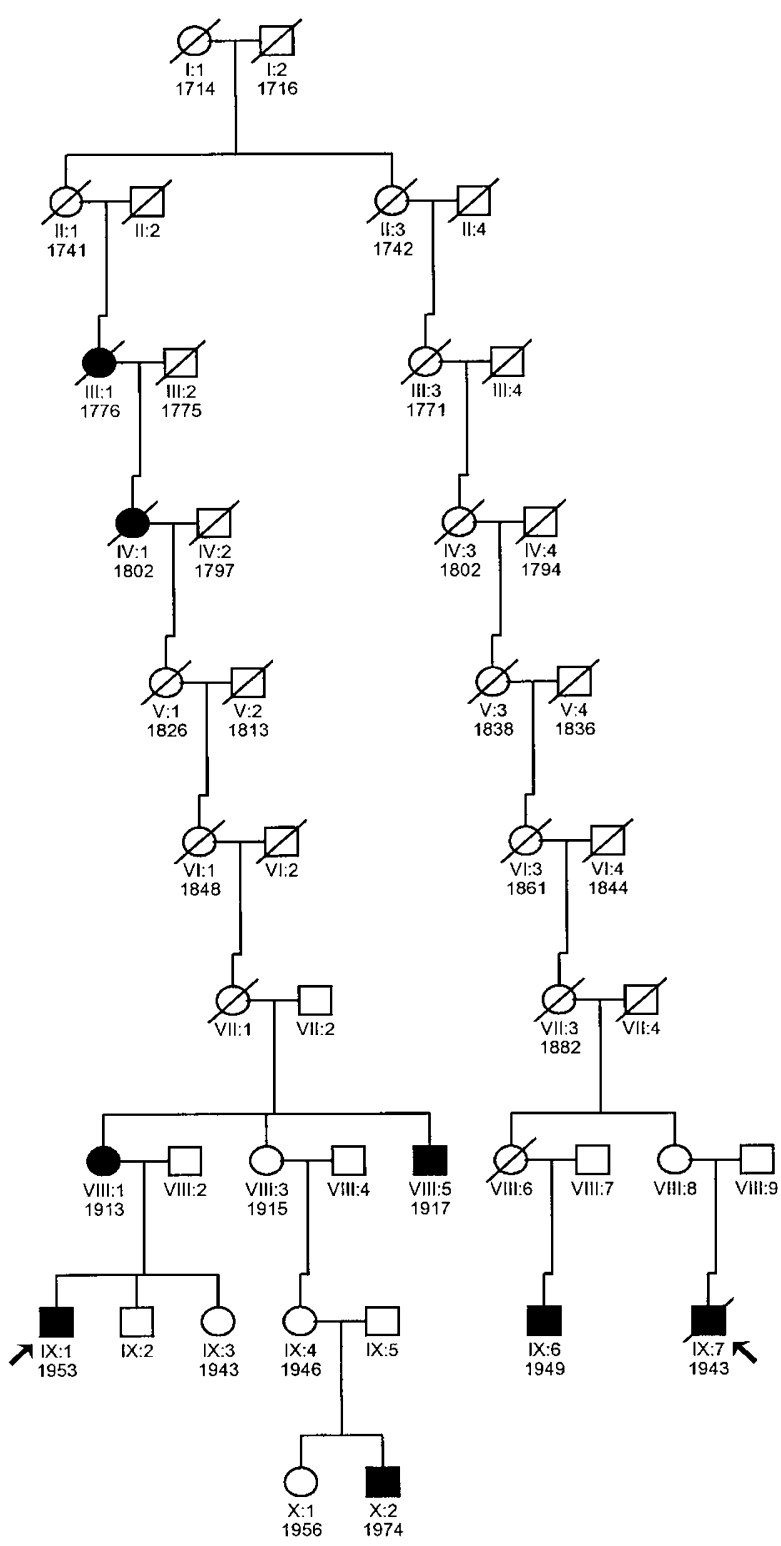

Figure 4 Abridged pedigree showing two cases, connecting and close relatives. Square: male; circle: female; solid: affected by LHON, two index cases marked with arrows, Case 1 left and Case 2 right.

\section{Discussion}

When evaluating whether the loss of vision from LHON in an HIV-infected patient may be coincidence, it is important to review the relative prevalence of the two conditions, which both predominantly affect young adult men. In Australia (population 18 million), over 2000 people (1/9000), from approximately 50 pedigrees, are estimated to be carrying a LHON mtDNA mutation. Of these, 150 people have lost vision from LHON ( $<10 \%$ of mutation carriers), with four new cases nationwide per year. ${ }^{15-17}$
In Australia, 21000 diagnoses of HIV infection were made up to April 2001, giving a prevalence estimate of $1000 / 100000$ people infected with HIV. ${ }^{18}$ Over the last decade (1990-1999), the estimates of HIV prevalence based on Red Cross Blood donation rates range from 0.5 to $1 / 100000$ and based on the Australian Defence Force screening range from 0 to $10 / 100000 .{ }^{19}$ Although the major gender and age of risk of LHON and HIV infection coincide, the chances of having both would be $1 / 9000 \times 21000$ or two cases, as we have found. However, the probability of these two HIV-positive, LHON-mutation carriers manifesting the optic neuropathy in a lifetime is more remote (one-tenth this rate) when one considers that, in Australia, 10-20\% of men and $2-4 \%$ of women who carry one of the three predominant mtDNA mutations will lose vision over their entire lifetime. ${ }^{20}$ Thus the two cases observed in 1 year are much higher than would be expected.

In view of the recent reports by Lüke et $a l^{6}$ of an HIV patient with the 11778 mutation, Shaik et $a l^{7}$ of a patient with the 11778 mutation, and Warner and Ries ${ }^{8}$ of a patient with the 14484 mutation in addition to the two cases described here with the 14484 mutation, it seems possible that antiretroviral treatments, through their effects on mitochondrial biogenesis, 'trigger' the onset of LHON in mutation carriers. There is a substantial body of experimental evidence that the nucleoside analogue reverse transcriptase inhibitors (NRTIs) affect DNA gamma polymerase, which is involved in mtDNA replication. ${ }^{9,10}$ This class affects the mitochondrial gamma polymerase enzyme to varying degrees, with stavudine, ddC, and Zalcitabine (ddC) being the most potent inhibitors of this enzyme, and abacavir, 3TC, and zidovudine the least potent. ${ }^{9}$ Many of the adverse effects of this class of antiretroviral agents are postulated to be secondary to mitochondrial toxicity. ${ }^{10}$ Both patients had evidence of mitochondrial toxicity secondary to nucleoside analogues. Patient 1 developed peripheral neuropathy 12 months before the onset of visual symptoms, and patient 2 had evidence of metabolic defects associated with mitochondrial toxicity including an elevated serum lactate level and peripheral neuropathy. Abnormal venous lactate levels after exercise have been reported in healthy carriers of LHON as well as in an individual with optic neuropathy. ${ }^{21,22} \mathrm{~A}$ mitochondrial deoxynucleotide carrier, which may be the predominant means by which the NRTIs enter the mitochondria and disrupt replication, ${ }^{11}$ has recently been identified.

One previous Australian 11778 LHON-mutation carrier was known to have died of AIDS secondary to Factor VIII contamination, but he was not reported to have lost vision prior to his death in 1991. Newman and Lessel $^{23}$ have reported bilateral optic neuropathy with 
recovery in two patients with HIV, one of whom was on zidovudine, but neither were known to harbour LHON-predisposing mutations.

Another striking feature of the two cases reported here is the severity of the visual loss. The 14484 mutation is usually associated with visual recovery and a milder final visual field loss. There is no other LHON patient in Australia who had a final acuity of 'no perception of light'. However, there was one case, with the 14484 mutation, reported to be 'no perception of light' for a short period ( $\mathrm{O}^{\prime}$ Day, personal communication). Recovery of vision is more likely to occur in patients with loss of vision under the age of 26 years (the median age of visual loss for LHON), but is still seen to a lesser degree in some older individuals. Although the two patients are in the upper centiles of age for visual loss, they are the two most severely affected individuals in over 50 affected cases in their large family. It is surprising and inexplicable that the degree of optic atrophy does not seem to parallel the severity of visual field loss, which is usually more marked at an early stage for most LHON patients even if they do recover vision.

A further interesting feature of patient 2 was the neurological deficits associated with the visual loss. This has been described previously in association with the 11778,3460 and $14484 \mathrm{mtDNA}$ mutations. These reports are of a 'multiple sclerosis-like' syndrome, involving movement disorders (ataxia, and tremor as case 2 experienced) and peripheral neuropathy. Similar features of T2 hyperintensity on MRI scanning of the brain have also been described. ${ }^{24-26}$

Given the possible pathophysiological mechanism of antiretroviral drugs of the nucleoside analogue class triggering LHON, and the severe nature of the visual loss, patients should be warned of the possible risk, especially if there is a family history of LHON or unexplained visual loss. It is difficult to discontinue antiretroviral treatment in HIV-infected patients with advanced disease, as was the situation in patient 1 . The brief period of 2 months when he was off antiretroviral treatment may have been too short to allow mitchondrial recovery or LHON recovery. It may be prudent to choose an antiretroviral regimen that does not include nucleoside analogues. It may soon be possible to recognize which particular medications are triggering LHON, and this information may shed more light on the underlying pathophysiology of LHON.

\section{References}

1 Riordan-Eva P, Sanders MD, Govan GG, Sweeney MG, Da Costa J, Harding AE. The clinical features of Leber's hereditary optic neuropathy defined by the presence of a pathogenic mitochondrial DNA mutation. Brain 1995; 118: 319-337.

2 Mackey DA. Misconceptions about Leber hereditary optic neuropathy. Med J Aust 1994; 160: 763-766.

3 Johns DR, Smith KH, Miller NR. Leber's hereditary optic neuropathy. Clinical manifestations of the 3460 mutation. Arch Ophthalmol 1992; 110: 1577-1581.

4 Berninger TA, von Meyer L, Siess E, Schon O, Goebel FD. Leber's hereditary optic atrophy: further evidence for a defect of cyanide metabolism? Br J Ophthalmol 1989; 73: 314-316.

5 Kerrison JB, Miller NR, Hsu F, Beaty TH, Maumenee IH, Smith KH. A case-control study of tobacco and alcohol consumption in Leber hereditary optic neuropathy. Am J Ophthalmol 2000; 130: 803-812.

6 Lüke C, Cornely OA, Fricke J, Lehrer E, Bartz-Schmidt KU. Late onset of Leber's hereditary optic neuropathy in HIV infection. Br J Ophthalmol 1999; 83: 1194.

7 Shaikh S, Ta C, Basham AA, Mansour S. Leber hereditary optic neuropathy associated with antiretroviral therapy for human immunodeficiency virus infection. Am J Ophthalmol 2001; 131: 143-145.

8 Warner JE, Ries KM. Optic neuropathy in a patient with AIDS. J Neuroophthalmol 2001; 21: 92-94.

9 Brinkman K, ter Hofstede HJM, Burger DM, Smeitink JAM, Koopmans PP. Adverse effects of reverse transcriptase inhibitors: mitochondrial toxicity as common pathway [editorial]. AIDS 1998; 12: 1735-1744.

10 Kakuda TN. Pharmacology of nucleoside and nucleotide reverse transcriptase inhibitor-induced mitochondrial toxicity. Clin Therapeutics 2000; 22: 685-708.

11 Dolce V, Fiermonte G, Runswick MJ, Palmieri F, Walker JE. The human mitochondrial deoxynucleotide carrier and its role in the toxicity of nucleoside antivirals. Proc Natl Acad Sci USA 2001; 98: 2284-2288.

12 Mackey DA, Howell NA. Variant form of Leber hereditary optic neuropathy characterized by recovery of vision and a multistep mitochondrial genetic etiology. Am J Hum Genet 1992; 51: 1218-1228.

13 Howell N, Kubacka I, Mackey DA. How rapidly does the human mitochondrial genome evolve? Am J Hum Genet 1996; 59: 501-509.

14 Luzhansky JZ, Pierce AB, Hoy JF, Hall AJ. Leber's hereditary optic neuropathy in the setting of nucleoside analogue toxicity. AIDS 2001; 15: 1588-1589.

15 Mackey DA, Buttery RG. Leber hereditary optic neuropathy in Australia. Aust NZ J Ophthalmol 1992; 20: 177-184.

16 Mackey DA. The epidemiology of Leber hereditary optic neuropathy in Australia. Clin Neurosci 1994; 2: 162-164.

17 Chan C, Mackey DA, Byrne E. Sporadic Leber hereditary optic neuropathy in Australia and New Zealand. Aust NZ J Ophthalmol 1996; 24: 7-14.

18 National Centre in HIV Epidemiology and Clinical Research. Australian HIV Surveillance Report, Vol. 17, 2001, $\mathrm{p} 13$.

19 National Centre in HIV Epidemiology and Clinical Research. http://www.med.unsw.edu.au/ncher.

20 Mackey DA. Mitochondrial diseases. In: Traboulsi EI (ed). Genetic Diseases of the Eye. Oxford University Press: New York, 1998, pp. 723-732.

21 Montagna P, Plazzi G, Cortelli P, Carelli V, Lugaresi E, Barboni $\mathrm{P}$ et al. Abnormal lactate levels after effort in 
healthy carriers of Leber's hereditary optic neuropathy. J Neurol Neurosurg Psychiatry 1995; 58: 640-641.

22 Ninomiya T, Yamazaki H, Munakate S, Yoshino H, Sato T. A case of Leber's hereditary optic neuropathy with elevated blood levels of lactate and pyruvate. Br J Ophthalmol 1997; 81: 422.

23 Newman NJ, Lessell S. Bilateral optic neuropathies with remission in two HIV-positive men. J Clin Neurophthalmol 1992; 12: 1-5.

24 Nikoskelainen EK, Marttila RJ, Huponen K, Juvenon V, Lamminen T, Sonninen P et al. Leber's 'plus': neurological abnormalities in patients with Leber's hereditary optic neuropathy. J Neurol Neurosurg Psychiatry 1995; 59: 160-164.

25 Funalot B, Ranoux D, Mas JL, Garcia C, Bonnefont JP. Brainstem involvement in Leber's hereditary optic neuropathy: association with the 14484 mitochondrial DNA mutation. J Neurol Neurosurg Psychiatry 1996; 61: 533-534.

26 Jansen PHP, van der Knaap MS, de Coo IF. Leber's hereditary optic neuropathy with the $11788 \mathrm{mt}$ DNA mutation and white matter disease resembling multiple sclerosis: clinical, MRI and MRS findings. J Neurol Sci 1996; 135: 176-180. 